\title{
Reflexiones sobre la igualdad en una era de desigualdades ${ }^{*}$
}

\author{
Pierre Rosanvallon
}

Para nadie es un misterio que las desigualdades han aumentado en forma explosiva. El fenómeno, que obedece primordialmente al enorme incremento de los ingresos más altos, ha sido objeto de numerosos estudios estadísticos. En los Estados Unidos, en 2010 el 10\% de las personas de mayores ingresos representaba un $50 \%$ del ingreso total, comparado con solo $35 \%$ en 1982. Hace poco la Oficina de Presupuestos del Congreso reveló que entre 1979 y 2007 el 1\% de los estadounidenses más ricos había duplicado con creces su participación en este ingreso total, de $8 \%$ a $17 \%$. En el mismo período, sus in-

Traducción no oficial del texto escrito de la conferencia dictada por el autor en el Centro de Estudios Públicos en octubre de 2011, en el marco de su visita a Chile como invitado de la Cátedra Globalización y Democracia de la Universidad Diego Portales. Estudios Internacionales agradece al profesor Rosanvallon la oportunidad de poder compartir sus reflexiones con nuestros lectores. gresos se elevaron $275 \%$, mientras que en el extremo inferior de la escala, las entradas del $20 \%$ de los estadounidenses más pobres se elevaron únicamente $18 \%$. En Francia, el ingreso medio del $1 \%$ más rico de la población aumentó $14 \%$ entre 1998 y 2006, mientras que el $0.01 \%$ de los que se encontraban en la cúspide de la escala aumentó casi $100 \%$, en circunstancias de que en el mismo período el $90 \%$ situado en el tramo inferior solo obtuvo un $4 \%$ más. Además, junto con las crecientes diferencias de ingreso se comprueba un incremento de la concentración de la riqueza. En los Estados Unidos, un $20 \%$ de las personas es dueña del $93 \%$ de los activos financieros ( propiedad raíz, cuyo valor se ha reducido). En Francia, el 1\% más rico posee el $24 \%$ de la riqueza del país y el 10\% de ellos es dueño del $62 \%$, mientras que el $50 \%$ menos rico solo accede al $6 \%$ de ella. Las cifras son comparables casi en 
toda Europa. La verdad es que medir las desigualdades es un problema complejo que plantea importantes interrogantes metodológicas y no hay duda de que el tema de la desigualdad es mucho más que una simple cuestión de ingresos y de riqueza. Los ejemplos podrían fácilmente extenderse indefinidamente, pero menciono estas cifras tan solo para plantear el escenario y dar una idea de la magnitud del fenómeno.

\section{EL FIN DE LA ERA DE LA IGUALDAD}

La creciente desigualdad contrasta marcadamente con su anterior baja en Europa y América. En rigor, no deja de ser sorprendente que el incremento reciente se produzca tras un prolongado período en que la desigualdad de los ingresos y de la riqueza se redujo en ambos continentes. En Francia, en 1913 el $1 \%$ de los más ricos poseía el $53 \%$ de la riqueza del país, pero en 1984 la cifra había caído a solo un $20 \%$. En los Estados Unidos, antes de la gran crisis el $10 \%$ de las personas que ganaban más se repartían casi el 50\% del ingreso total, pero menos del $35 \%$ desde 1950 hasta mediados de los años ochenta. En Suecia, notable ejemplo de reducción de la desigualdad, en 1980 el 1\% de los que ganaban más obtuvo solo un $23 \%$ del ingreso total, comparado con el $46 \%$ al término del siglo 20 . Una obra aparecida hace poco ${ }^{11}$. se refiere al siglo 20 como The Age of Equality.

1 Pomfret, Richard (2011), The Age of
En menos de 20 años (1900-1920) se produjo un quiebre profundo respecto del siglo 19 (hecho que se reafirmó y aceleró después de cada una de las dos guerras mundiales). Estas grandes bajas de la desigualdad se lograron gracias al aumento acelerado de los ingresos bajos, al menor dinamismo del incremento de los ingresos altos, a los pagos de transferencia por concepto de beneficios sociales y a un sistema tributario altamente progresivo, que gravaba los tramos más altos con tasas cada vez mayores. Hoy en día este legado se ha disipado y el sistema actual rompe abruptamente con el pasado e invierte la tendencia del siglo anterior. Al parecer, regresamos al siglo 19 ..

De ahí que corresponda preguntarse dos cosas:

En primer lugar, ¿cómo entender este "gran retroceso", tan profundo como lo fue la "gran transformación» descrita por Karl Polanyi? Los impuestos son un reflejo de este vuelco. Cualquiera que fuese la fisonomía ideológica del gobierno en el poder, en todas partes se redujo la progresividad del impuesto a la renta. En Suecia, la tasa marginal máxima se redujo de $87 \%$ en 1979 a $51 \%$ en 1983. En Gran Bretaña ella bajó de $83 \%$ en 1977 , año de la muerte de Tony Crosland, a 40\% en 1999 (mientras que la tasa disminuyó de $35 \%$ a $23 \%$ ). A comienzos del siglo 21 en ningún país desarrollado se aplicaba una tasa marginal superior al $50 \%$. El cambio era fenomenal, tan espectacular

Equality: The Twentieth Century in Economic Perspective, Belkamp. 
como había sido el incremento de estas tasas desde que se comenzó a aplicar el sistema de progresividad del impuesto a la renta a comienzos del siglo 20 (a partir de tasas marginales máximas de $2 \%$ a $5 \%$, que en los Estados Unidos llegaron a un máximo de $94 \%$ veinte años después).

$\mathrm{Y}$ ¿cómo comprender que por lo general casi en todas partes se critican estas desigualdades, en circunstancias de que paradójicamente parecen tolerarse los mecanismos que las producen (por ejemplo, se denuncian las primas que obtienen los comerciantes o los sueldos que ganan los gerentes, pero no los ingresos equivalentes que se perciben en el deporte o en el rubro de los espectáculos).

En la época actual estas interrogantes son clave porque ponen en peligro la democracia. Esta da prueba de su vitalidad como sistema al mismo tiempo que languidece como forma social. Los ciudadanos ya no se contentan con hacerse oir esporádicamente en las urnas sino que ejercen un poder cada vez más activo de supervisión y control. La propia fuerza de su crítica del sistema representativo revela que están resueltos a mantener vivo el ideal democrático. Esta es una característica de nuestros tiempos. El deseo de aumentar la libertad y crear poderes que respondan a la voluntad general ha derribado déspotas por doquier y ha cambiado la faz del mundo. Pero el «pueblo», entendido en su sentido político como entidad colectiva que impone su voluntad con creciente energía, es cada vez menos un «órgano social». La ciudadanía política ha avanzado, mientras que la ciudadanía social ha retrocedido. Esta expresión de la democracia es el fenómeno más importante de nuestro tiempo y constituye una amenaza peligrosa para nuestro bienestar. Si persiste, el propio sistema democrático podría terminar por verse en peligro. El aumento de los movimientos populistas es a la vez un índice de este peligro y su fuerza motriz.

\section{CÓMO ENTENDER LA «GRAN TRANSFORMACIÓN» ANTERIOR}

El quiebre con el capitalismo del siglo 19 puede explicarse por tres factores:

- El desarrollo de un «reformismo del temor»

- El efecto de las dos guerras mundiales

- La des-personalización del mundo producida por las transformaciones morales y sociológicas.

\subsection{El reformismo del temor}

A fines del siglo 19, el desarrollo del movimiento obrero y su proyección en votos socialistas (con el sufragio universal) ejerció presión sobre los gobiernos conservadores. "Debemos elegir entre una revolución fiscal y una revolución social» concluía en Francia Emile de Girardin. Al respecto, el ejemplo más claro es el de Alemania. Para Bismarck, la opción reformista era indudablemente un 
cálculo político: su finalidad inmediata era contrarrestar la difusión de las ideas socialistas mostrando que al gobierno le preocupaba la clase trabajadora. El propio Kaiser respaldó esta estrategia. En un mensaje al Reichstag sostuvo que: «Para que cicatricen las heridas de los trabajadores no solo tenemos que reprimir los excesos de la social democracia sino también, con un ánimo más positivo, promover el bienestar de los trabajadores». En otras palabras, en Alemania el plan para reducir las desigualdades sociales y compensar las vicisitudes del empleo de la clase obrera se originó en lo que podríamos llamar reformismo del temor. La mayoría de los demás países de Europa siguió el ejemplo de Alemania. La tendencia cobró impulso con el poder creciente de los partidos socialistas en las urnas (reforma que indudablemente ayudó a limitar el descontento social pero que en definitiva demostró que este era irreversible). De ahí que liberales y conservadores «se resignaran a las reformas» para responder a las advertencias alarmistas de que la sociedad capitalista, en la forma en que se había desarrollado hacia mediados del siglo 19, era insostenible. "Con el tiempo, demasiada desigualdad de riqueza y de ingresos y exceso de lucha de clases terminará por socavar los sistemas políticos» sostuvieron los economistas y sociólogos alemanes que firmaron el Manifiesto de Eisenach en 1872, proporcionando así un marco intelectual y moral para justificar el cambio de las políticas internas de Bismarck.
«Siempre se puede evitar la revolución mediante una reforma oportuna» afirmaba Gustav Schmoller, uno de los principales socialistas del movimiento.

Después de 1918, el resurgimiento del temor a la revolución aceleró los cambios en Europa y la revolución de octubre instaló el espectro de la insurrección en otros lugares. Por otra parte, el leninismo hizo que el voluntarismo político volviera a ser respetable, de manera que algunos socialistas -que terminarían por afiliarse a los partidos comunistas- ya no se contentaron con esperar la inevitable desintegración del capitalismo avanzado. En 1919 en Europa se produjo una serie de levantamientos revolucionarios estimulados por el ideal soviético. En Alemania fueron los espartaquistas encabezados por Karl Liebknecht y Rosa Luxemburgo; en Hungría, Bela Kun derrocó el gobierno establecido por la revolución burguesa y proclamó la república soviética húngara. En todas partes se produjeron grandes huelgas que hicieron tambalear a los gobiernos establecidos. «Toda Europa piensa en la revolución» advirtió Lloyd George en la Conferencia de paz el 25 de marzo de 1919. «Los trabajadores están profundamente descontentos con las condiciones imperantes antes de la guerra. Están iracundos e indignados. De un extremo a otro de Europa las masas están poniendo en entredicho el orden social, político y económico existente». Además, había aumentado mucho la influencia de los trabajadores, que estaban ampliamente organizados. 
En los años inmediatamente posteriores a la guerra se disparó la afiliación a los sindicatos. En Gran Bretaña, la cifra de trabajadores sindicalizados se elevó a 8.3 millones, en comparación con 4.1 millones antes de la guerra, en Alemania aumentó a 7.3 millones y en Francia se cuadruplicó (de 400.000 a 1.6 millones). En consecuencia, había que habérselas con la fuerza de los trabajadores. Todos estos factores sociales y políticos se unieron para estimular a los gobiernos a ampliar y acelerar las reformas iniciadas antes de la guerra.

\subsection{Las guerras mundiales y la nacionalización de la vida}

La evolución de las desigualdades está estrechamente relacionada con la indiferencia de algunos respecto de la forma en que funciona comúnmente la humanidad y con la legitimación del derecho a diferenciarse y separarse de los demás. Por lo tanto, por construcción se vincula con el hecho de atribuir mayor valor a las normas privadas que a las públicas. La experiencia de la Primera Guerra Mundial invirtió esta tendencia en el sentido de que nacionalizó la vida de las personas. La actividad privada se determinó en gran medida por restricciones colectivas, a raíz de lo cual las relaciones sociales tendieron a polarizarse entre dos extremos: retirarse al círculo familiar o ser absorbidos por los problemas superiores del país. Prácticamente no quedó espacio intermedio entre la familia y el país. La preocupación por la familia inmediata y la angustia por el destino del país absorbió la energía de todos.

La sociedad civil se redujo en consecuencia y quedó relegada a un lugar secundario en relación con la familia y la nación. La obligada simplificación de la vida social y el ascenso de la nación a la condición de comunidad que atravesaba por una severa prueba transformó radicalmente las condiciones de la vida política. Adquirió cuerpo la idea de que toda persona tiene una deuda social con la comunidad. El hecho de que la guerra amenazara la supervivencia de todos hizo que los principios fundamentales del estado social de naturaleza parecieran bastante reales.

En consecuencia, la revolución redistributiva derivó del contexto de la Primera Guerra Mundial. Los millones de muertos del continente europeo obligaron a las personas a reflexionar de manera nueva sobre aquello que las unía, "Si la guerra no te mató, te hizo pensar» dijo George Orwell. Por cierto, los soldados se llevaron la peor parte. Cada combatiente aprendió en el lodo de las trincheras que su vida era tan vulnerable como la de su camarada ya que todos volvieron a algo parecido a un estado de naturaleza. Nadie expresó mejor este sentimiento que Ernst Jünger. En Storm of Steel ensalzó la emoción del poder y la voluntad que encontró en el combate, pero también exploró lo que denominó experiencia interior del frente de batalla. «He estado una eternidad en esta trinchera» escribió «tal eternidad que uno tras otro han muerto mis sentidos $y$, perdido en el 
mar de la noche, me he convertido en parte de la naturaleza». Los soldados de infantería experimentaron la igualdad de condiciones en la forma extrema de un regreso a la naturaleza, en el límite entre la humanidad y la bestialidad la existencia desnuda. Viviendo con el terror de morir conocieron la igualdad de ser carne de cañón. "La conciencia de ser parte de una comunidad de naturaleza dio lugar a una sensación de igualdad muy vívida y reconfortante» escribió uno de ellos. Al experimentar esta clase de unidad constituyeron también una nación de manera nueva, derechamente física. Como dijo Robert Musil «Muchos soldados alemanes tuvieron por primera vez la jubilosa sensación de tener algo en común con todos los demás alemanes. De súbito, uno se convertía en una partícula simple y modesta de un suceso que trascendía lo personal. Inmerso en la nación, uno casi podía sentirla.» La muerte adquiría así sentido como forma de participación en la vida de la comunidad.

La experiencia de la Primera Guerra Mundial constituyó por tanto un hito decisivo en la modernidad democrática. De manera directa y manifiesta restableció la idea de una sociedad de semejantes. Revivió el sentido más antiguo de la idea de igualdad, captado por la palabra griega omiòi. En su primera acepción, el epíteto se aplicaba a la palabra polemos, o combate, caracterizaba una batalla que «es igual para todos, no perdona a nadie». En consecuencia, los omioï eran iguales en el sentido de que habían peleado juntos y compartido la misma suerte del soldado en el campo de batalla. La Primera Guerra Mundial no solo puso de manifiesto este aspecto de la igualdad mediante la experiencia fraterna del combate sino que la validó públicamente en todos los países que participaron en el conflicto mediante la organización de funerales nacionales para honrar al «soldado desconocido" caído en el campo de batalla. El culto del soldado desconocido fue montado cuidadosamente de manera de destacar su significado simbólico, dando fe de la importancia que tenía el más humilde ciudadano como representante de toda la nación. El anonimato del soldado desconocido expresó de manera ejemplar la idea de igualdad extrema, de valor estrictamente equivalente: el más humilde individuo encarnaba lo mejor de cada uno y se convirtió en la medida última del orden social. En 1918 el hombre común pasó a personificar el ser social.

La fraternidad en el combate y la conmemoración del sacrificio son fenómenos complejos, pero ayudaron a preparar el camino hacia una mayor solidaridad social. Los beneficios otorgados a los ex combatientes condujeron a replantear de manera general las prestaciones sociales y otras transferencias de carácter redistributivo. Así, en el caso de Francia, la primera ley importante de seguro social, la ley de 1928, fue presentada por sus patrocinadores como una ley «surgida después de la guerra a partir de la solidaridad de que habían dado fe las diversas clases de sociedad, de la determinación de otorgarles a quienes habían defendido a la Madre patria en 
las trincheras, a los miembros de las clases populares que se vieron obligados a defender la riqueza común, la ayuda necesaria para que pudieran enfrentar días difíciles y a partir de la gran idea de solidaridad nacional». A través de toda Europa se utilizaron los mismos argumentos para justificar las reformas sociales de la posguerra.

El propio Estados Unidos surgió de la guerra profundamente transformado. La experiencia modificó las actitudes de los estadounidenses respecto de los impuestos y de la redistribución. Cunado se aprobó la Ley de la renta de 1917 se habló de "conscripción del ingreso" y de "conscripción de la riqueza» en un momento en que los jóvenes estaban ingresando en masa a las fuerzas armadas. «Dejen que sus dólares mueran también por su patria» dijo un parlamentario. En los Estados Unidos, el llamamiento a dar muestras de patriotismo fiscal ayudó a legitimar el impuesto progresivo a la renta. De ahí que pueda decirse que después de la Primera Guerra Mundial todas las democracias capitalistas reexaminaran sus principios básicos y sus instituciones.

\subsection{La despersonalización del mundo}

La revolución redistributiva fue posible por las condiciones históricas y políticas recién mencionadas, pero además fue fruto de una revolución intelectual y moral que permitió pensar en una redistribución. En suma, fue posible debido a que la economía y la sociedad fueron «despersonalizadas» por pen- sadores que rechazaron los conceptos más antiguos de responsabilidad y talento individuales. En definitiva, lo que surgió fue una nueva percepción de la empresa.

Una manera nueva de entender la naturaleza de la sociedad cambió la forma en que las personas concebían la igualdad y la solidaridad a fines del siglo 19. Los fundadores de la sociología europea -Albert Schaeffle en Alemania, J.A.Hobson y L.Y. Hobhouse en Inglaterra, Albert Fouillé en Francia- concordaron en que la sociedad es un todo orgánico. Sin embargo, si incursionamos en la vasta bibliografía sociológica del período encontramos diferencias importantes de sensibilidad y discordancias en materia de teoría. Por ejemplo, se observa un apreciable vacío entre el uso de la metáfora orgánica y su interpretación práctica. El «organismo contractual» de Fouillé difiere mucho de los «órganos sociales» de Schaeffle. Sin embargo, en todos los casos se comprueba claramente el rechazo de los anteriores conceptos liberales individualistas sobre los fenómenos sociales. El nuevo criterio influyó de manera difusa pero significativa en la cultura politica y la filosofía social lo que para nuestros fines es quizá más importante que su contribución a la naciente ciencia de la sociología.

Socialistas de la escuela en Alemania, fabianos y nuevos liberales en Gran Bretaña y republicanos solidaristas en Francia: a fines del siglo 19 todos estos movimientos políticos e intelectuales convergieron. Los tres replantearon 
en términos muy similares la cuestión de cómo está constituida la sociedad. La idea de una sociedad compuesta de personas soberanas, autosuficientes, cedió lugar a un criterio basado en la interdependencia. «El hombre aislado no existe» sostuvo León Bourgeois, autor de Solidarité, obra que orientaría a una generación de republicanos y radicales hacia la refundación de su cultura política. En la obra Liberalism, que desempeñó un papel similar en Inglaterra, L.T.Hobhouse sostuvo también que cada persona está constituida por el «ambiente social» que la rodea. La revolución de Pasteur puso de relieve la idea de que el individuo es un ente fundamentalmente social. "Gracias a Pasteur., dice Bourgeois, «la idea de una humanidad nueva penetró en la mente de la gente. Fue él quien nos ofreció un concepto más preciso de las relaciones entre las personas; él quien demostró finalmente la profunda interdependencia que existe entre todos los seres humanos; él quien al formular de manera tan convincente la doctrina microbiana nos mostró hasta qué punto cada uno de nosotros depende de la inteligencia y de la moral de los demás.

En este nuevo marco, se redefinieron por completo las ideas de derecho y deber, mérito y responsabilidad, autonomía y solidaridad. No solo se pudo concebir la igualdad como redistribución, sino que ella se tornó posible. Así, la introducción del impuesto a la renta progresivo y la reforma de las contribuciones sobre los bienes raíces se relacionaron estrechamente con la creciente popularidad de la idea de deuda social que plantea
Bourgeois en Solidarité. Para él, todos nacemos con una deuda con la sociedad. Toda persona debe algo al trabajo acumulado por toda la humanidad. El individuo llega al mundo con toda clase de obligaciones para con la sociedad.

Además de «pagar la deuda social», el principio redistributivo implícito en el impuesto progresivo a la renta tenía una razón estructural. Al tener en cuenta el carácter socializado de la producción moderna el impuesto permitía corregir la distribución del ingreso determinada por el mercado y por tanto derivada de los principios de libertad individual y propiedad privada. Al ser interdependiente, el sistema de producción impedía aislar el aporte de cada persona. Hobhouse se burló de la afirmación de que el «self-made man» es el único responsable de su éxito. «Si hurgara hasta el fundamento de su fortuna» dijo "comprobaría que es la sociedad la que defiende y garantiza sus bienes y es socio necesario en su creación». Bourgeois resumió el punto sosteniendo que: "es imposible hacer cuadrar la cuenta de cada persona». Los dos grandes teóricos estadounidenses de la reforma tributaria, Richard T. Ely y Edwin R.A.Seligman, utilizaron el mismo argumento en el escrito en que abogan por un impuesto progresivo a la renta. «En el mundo moderno no existe nada que se asemeje a una producción de riqueza estrictamente individualista» dijo Ely. En todas partes, esta nueva manera de concebir la economía y la sociedad estaba implícita en el impuesto progresivo. Se consideraba que el nuevo 
impuesto era un mecanismo necesario de socialización, una manera de corregir la tendencia del mercado proclive a la privatización y la personalización. En otras palabras, la justicia social ya no se basaba en un imperativo moral de caridad; por el contrario, la requería la propia estructura social. En consecuencia, la noción de solidaridad en el orden socioeconómico tendía a traslaparse con la de ciudadanía en el orden político: eran dos maneras diferentes de concebir la sociedad como un todo orgánico.

El nuevo concepto emergente de nación incluía la idea de una sociedad redistributiva. En vez de concebir la nación exclusivamente en función de una identidad heredada, las personas comenzaron a concebirla como un modelo que debía lograrse democráticamente. Leon Buorgeois caracteriza este concepto: la nación, dice, «no debe reducirse a la decisión de defender a la patria de los peligros provenientes del exterior. Impone un deber mayor, un deber tanto en lo interno como en lo externo, un deber de justicia, paz y fraternidad, porque la paz y la fraternidad internas siempre están en peligro». En otras palabras, ahora muchos pensaban que las normas de justicia y las instituciones redistributivas eran fuentes adicionales de solidaridad nacional.

\subsection{Un concepto nuevo sobre la pobreza y la desigualdad}

El desarrollo del Estado de bienestar y de las instituciones redistributivas era inducido por el creciente reconocimien- to del carácter social de la desigualdad. Las personas estaban cada vez más dispuestas a concebir que la causa estructural de la desigualdad era más bien la forma en que estaba organizada la sociedad y no las diferencias individuales, objetivas y justificables. Fue gracias a esta nueva representación de la sociedad que en la primera mitad del siglo 20 aumentaron su influencia los críticos socialistas del orden social. El cambio fue particularmente pronunciado en Inglaterra, país de Europa donde a fines de siglo las diferencias de clase eran más profundas. La manifiesta importancia que la riqueza heredada en Gran Bretaña, donde existía un casi increíble grado de concentración de la propiedad de la tierra, incentivó las demandas en pro de reducir la desigualdad. En Equality, R.H.Tawney, uno de los grandes clásicos del pensamiento social inglés, sostuvo que la eliminación de las desigualdades estructurales que había en Inglaterra era simplemente señal de una «sociedad civilizada». Pese a reconocer que las diferencias individuales eran fuente de energía social positiva, no había razones para sostener que había que relacionarlas con un alto grado de desigualdad. Las diferencias entre las personas serían igualmente importantes si disminuía la desigualdad.

También cambiaron los conceptos sobre la pobreza. Gran Bretaña también marcó la pauta para Europa en este caso. Después de Tawney, neofabianos de la posguerra como Anthony Crosland, Richard Crossman y Roy Jenkins reflexionaron sobre la necesidad de 
aumentar la igualdad y sostuvieron que la pobreza era consecuencia de la disfunción social.

\subsection{La empresa como organización}

La historia del Estado de bienestar se relacionaba estrechamente con el lugar dominante que ocupaban las ideas keynesianas sobre macroeconomía, con su consiguiente énfasis en la demanda. Redistribuir la riqueza era contribuir al crecimiento. Al mismo tiempo, adquirió importancia un nuevo enfoque «posliberal» sobre la empresa. Autores como Andrew Shonfield, John Kenneth Galbraith y Peter Drucker son ejemplo de la nueva manera de concebir la empresa que adquirió influencia en los años 1960, cuando alcanzó su apogeo el modelo de redistribución social. A continuación, utilizaremos sus ideas a manera de guía.

En Modern Capitalism (1965), Schonfield sintetizó un amplio estudio sobre Europa y los Estados Unidos y describió la empresa industrial privada moderna como organización que «se ve como institución permanente, encargada de funciones que van más allá de la maximización de las utilidades y que suelen ser incompatibles con ella». En realidad, el estilo de las empresas «recordaba cada vez más a algunas instituciones públicas». A su juicio, si bien es cierto que la competencia no había desaparecido, habían surgido las grandes empresas que por su gran tamaño podían «domesticar el mercado». En otras palabras, las grandes empresas ya no están sujetas a las fluctuaciones disociadoras del mercado en el corto plazo. De hecho, los tres autores mencionados concordaban en que la economía de mercado había llegado a su fin. «El sistema industrial moderno» sostuvo Galbraith «ya no es fundamentalmente un sistema de mercado. Es planificado en parte por las grandes empresas y en parte por el Estado moderno. Exige planificación porque la tecnología y la organización modernas solo pueden fructificar en un medio estable, condición que el mercado no puede satisfacer». Según Galbraith, las empresas modernas se habían convertido en organizaciones relativamente autónomas. En gran medida autofinanciadas, no necesitaban depender de la bolsa de valores y se habían liberado mucho del poder de los accionistas, que se contentaban con percibir «dividendos razonables».

«En la gran empresa moderna» concluye Galbraith «el poder ha pasado inevitable e irrevocablemente del individuo al grupo, porque solo el grupo cuenta con la información necesaria para tomar decisiones». Esta observación era fundamental para su descripción de lo que podría denominarse «despersonalización» del poder y socialización de la responsabilidad. Para el autor de The New Industrial State, esta transferencia del poder a a la organización tenía una serie de consecuencias. Primero, indicaba que había desaparecido el empresario schumpeteriano. «En la empresa industrial 
desarrollada el empresario ya no existe como individuo", ha sido reemplazado por la tecnoestructura, verdadera mente colectiva. El advenimiento de este poder impersonal indicaba también que el éxito de la empresa dependía más de la calidad de su organización y de la pertinencia de sus métodos de gestión que de la excepcionalidad de los talentos de una u otra persona. En consecuencia, podía funcionar bastante satisfactoriamente aunque su personal estuviese compuesto de personas totalmente corrientes. El punto es lo suficientemente importante como para justificar otra cita: «El verdadero éxito consiste en coger personas normales, capacitarlas cuidadosamente y luego, mediante una organización adecuada, asegurarse de que sus conocimientos se sumen a aquellos de otros especialistas igualmente corrientes. Esto permite prescindir de la necesidad de contar con genios. El resultado es menos impresionante, pero mucho más previsible». Por lo tanto, se bajaba el talento de su pedestal. Peter Drucker sostuvo exactamente lo mismo.

Para Galbraith, estos cambios significaban que el papel del gerente general de la empresa se limitaba al de ser simplemente un elemento más de la maquinaria de la organización, lo que podía comprobarse en la posibilidad de intercambiar papeles. Para la General Motors o la Continental Can «La jubilación, el fallecimiento o el reemplazo de un mandamás de la industria, por importante que fuera, no tenía consecuencia alguna». El gerente general de una gran empresa pasa al olvido tan pronto abandona su cargo y «lo único que le espera es la oscuridad de la Estigia». Los ejecutivos, al igual que los demás empleados, se habían convertido en «hombres de la organización». Eran meros servidores. El prestigio era de la organización y no de sus miembros.

A juicio de Galbraith la socialización de la responsabilidad y de la productividad que acarrea esta clase de organización modificó la naturaleza de la cuestión social. La eficiencia productiva del sistema inevitablemente redistribuirá la riqueza y reducirá la desigualdad. La suerte del individuo mejora gracias a lo que se considera logros colectivos. Nadie podía pretender que ellos sean personales. Por cierto, los ejecutivos ganan más que los trabajadores, pero solo dentro del marco de una jerarquía funcional de destrezas técnicas (y cabe recordar, por ejemplo, que en su época Peter Drucke sostuvo que la relación entre la remuneración del más alto ejecutivo y aquella del más humilde obrero no debería pasar de 20:1).

Gablbraith y Drucke no fueron en absoluto originales cuando describieron la evolución de la empresa. Aunque no siempre dijeron claramente qué partes de su descripción correspondían a hechos y cuáles eran simplemente especulativas, sus puntos de vista fueron ampliamente compartidos a través del mundo industrializado. El ethos igualitario de la época guardó estrecha relación con esta imagen de un mundo profundamente socializado. 


\section{Cómo COMPRENDER EL «GRAN VUELCO»}

Si se tienen en cuenta los factores políticos e históricos de la "gran transformación» previa se comprende fácilmente que ellos han dejado de ser aplicables. Tras la caída del comunismo, ya no hay lugar para un reformismo basado en el temor. Subsisten los temores sociales, pero ellos se relacionan con hechos como la violencia, la seguridad o el terrorismo. Resultan atractivos para un Estado autoritario, pero no para uno solidario. Del mismo modo, las amenazas ecológicas ponen el acento en el destino de las generaciones futuras de manera general y abstracta y no en cuestiones relacionadas con la redistribución social. Por otra parte, Europa ha sido un continente de paz desde 1945 y no se han producido grandes conmociones que den lugar a un replanteamiento del contrato social. Sin embargo, y lo que es más importante, hay que tener presente el impacto de la transformación del capitalismo y de la sociedad.

\subsection{El capitalismo de la singularidad: el sentido de un cambio}

El capitalismo que comenzó a surgir en los años ochenta fue en dos sentidos distinto de las primeras formas de capitalismo organizado. En primer lugar, cambió su relación con el mercado, como también el papel asignado a los accionistas. Segundo, el trabajo se organizó de manera diferente. La organización al estilo de Ford, basada en la movilización de grandes masas de trabajadores cedió paso a un nuevo énfasis en la capacidad creadora de las personas. Ahora, lo más importante era la capacidad de reaccionar rápidamente al cambio de las circunstancias; se redujo el antiguo énfasis en la disciplina en el lugar de trabajo. En consecuencia, el trabajo se tornó más singular por dos razones. Primero, cambió la naturaleza de la producción. Las propias nuevas tecnologías de la información y de las comunicaciones eran producto del conocimiento y las tecnologías nuevas incorporaban conocimientos científicos de maneras fundamentales. El ingenio se convirtió así en el principal factor de producción. Para describir este cambio se acuñaron frases como «capitalismo cognitivo» y «subjetividad productiva». En segundo lugar, el desarrollo de la economía de servicios se tradujo en la creciente importancia de la calidad de las relaciones con la clientela En el sector de servicios, estas relaciones son fundamentales y al respecto también puede hablarse de una singularización del proceso de trabajo. Este cambio es evidente en campos tales como los servicios de salud, consultoría y enseñanza, así como en oficios especializados como la gastronomía. Pero también se aplica a los servicios de entrega a domicilio y reparaciones en el hogar, industrias que actualmente figuran entre los mayores empleadores de quienes clasifican como «trabajadores». En consecuencia, la $\mathrm{ca}$ lidad se ha convertido en característica central de la nueva economía, marcando un quiebre profundo con la antigua eco- 
nomía de la cantidad. Por lo tanto, las labores habituales se han diversificado y ha aumentado la variedad de productos ofrecidos.

El modo de producción del nuevo capitalismo de la singularidad fue configurado por una economía en innovación permanente. Esto se comprueba en el hecho de que entre 1950 y 1980 la lista de las principales empresas de los grandes países industrializados se mantuvo relativamente constante. Algunas de ellas existían desde hacía decenios, pero en los años 1990 la jerarquía cambió apreciablemente. Solo en los Estados Unidos las empresas principales clasificadas en función de su capitalización en la bolsa de valores eran relativamente nuevas, como $\mathrm{Mi}$ crosoft, Apple y Oracle, mientras que muchas, que alguna vez habían sido gigantes, habían desaparecido. El panorama industrial y financiero cambió en todas partes y esto aceleró aún más el cambio a nuevas formas de organización y movilización de la mano de obra.

\subsection{La metamorfosis del individualismo}

Estos cambios, que precipitaron una crisis en las sociedades que se regían por la idea de la igualdad como redistribución, también tuvieron una arista sociológica. Ello no se percibe fácilmente porque el individualismo desenfrenado fue objeto de grandes críticas. De acuerdo con estas, la búsqueda de la riqueza había socavado la solidaridad social y estimulado la privatización.
Si bien es cierto que en cierta medida los críticos tenían razón, sus opiniones no nos ayudan a comprender el origen del fenómeno. En especial, pasan por alto una paradoja sorprendente: la nueva era de desigualdad y caída de la solidaridad también se ha caracterizado por una mayor conciencia de la discriminación social y por la tolerancia respecto de numerosas clases de diferencias. El panorama es por decir lo menos contradictorio y aunque se ha perdido algún terreno no puede negarse que se han producido avances respecto de la condición jurídica de la mujer, la aceptación de las diferencias en materia de orientación sexual y de los derechos individuales en general. Para comprender los cambios experimentados por nuestras sociedades en el último tiempo es preciso tener presentes todas estas tendencias divergentes. Una manera de hacerlo es examinar la transformación producida al interior de la «sociedad de individuos». Ella no se produjo de improviso a fines del siglo 20 ya que durante más de doscientos años ha constituido el marco dentro del cual se han desarrollado las instituciones modernas. En pocas palabras, lo que debemos entender es la transición de un individualismo de universalidad a un individualismo de singularidad.

\subsection{El individualismo de la universalidad \\ El individualismo revolucionario no se relaciona con un estado social ni con un hecho moral. Como vimos el}


término no surgió en el período revolucionario. Describe la formación del hombre a la vez como ente jurídico -sujeto de derechos que le garantizan la libertad de conciencia y de expresión, de propiedad y autonomía- y como sujeto político, que comparte la soberanía mediante el ejercicio del derecho a voto. En consecuencia, define una manera de construir sociedad, esto es, un criterio nuevo para crear un orden social y político que reemplace el antiguo orden corporativista y absolutista. Por lo tanto, el individualismo revolucionario se vinculaba estrechamente con la idea de igualdad y reconocimiento de la semejanza humana. Caracterizaba una forma de relacionarse, un tipo de vínculo social y no la condición de un solo átomo social considerado en forma aislada. Georg Simmel utilizó la expresión individualismo de la semejanza para describir en términos generales la tendencia de las sociedades europeas en el siglo 18. A su juicio, las aspiraciones de autonomía y libertad guardaban estrecha relación con un ethos igualitario universalista. Sostenía que el punto de vista individualista "obedecía al supuesto de que, liberadas de cadenas sociales e históricas, la personas resultarían ser fundamentalmente similares entre sí». En este contexto, la libertad y la igualdad eran valores superpuestos. Una vez eliminados los órdenes, disciplinas y estructuras, las personas podrían reafirmarse plenamente como seres humanos. Todos se convertirían simplemente en personas.

\subsection{El individualismo de la diferencia}

Con la decadencia del Antiguo Régimen, el aspecto sicológico del individualismo se logró más plena y reconociblemente en el medio artístico. Este le dio profundidad existencial a lo que antes se había manifestado principalmente en forma caricaturesca en la corte real. Los artistas definieron su identidad en función de su disidencia respecto de la marcha común de la humanidad. Dieron la espalda a una sociedad burguesa definida por el conformismo, esto es, por el hecho de que la clase burguesa no puede existir sino como prisionera de sus propios objetivos estrechos y su falta de imaginación. Los artistas también se mantuvieron al margen de las masas supuestamente gregarias, que a su juicio eran esclavas de intereses personales inmediatos y de pasiones irreflexivas. Este individualismo de la diferencia fue precursor del actual individualismo de la singularidad.

\subsection{El individualismo de la singularidad}

El individualismo de la singularidad puede concebirse como una generalización del individualismo de la diferencia. Esta se convirtió en lugar común y perdió sus connotaciones elitistas: en suma, se «democratizó». El proceso dio comienzo a una nueva etapa de la emancipación humana, definida por el deseo de lograr una existencia plenamente personalizada. Su advenimiento guar- 
dó estrecha relación con el incremento de la complejidad y la heterogeneidad de la vida social y en consecuencia, con cambios de las características del capitalismo. A un nivel más profundo, también se vinculó con el hecho de que ahora la vida de cada individuo se determina más por su historia personal que por una condición personal.

Otra señal de esta evolución es el hecho de que ha cambiado la naturaleza de la desigualdad. Si bien es cierto que continúan existiendo desigualdades entre los distintos grupos sociales (ricos y pobres, ejecutivos y trabajadores, etc.) en cierta medida estos grupos se han individualizado y esto modifica la forma en que ellas son percibidas. Actualmente las desigualdades son al mismo tiempo resultado de situaciones (individuales) que se están diversificando y de condiciones (sociales) que se reproducen. Para los economistas, estas desigualdades nuevas se dan «al interior de las categorías».

El individualismo de la singularidad también es reflejo de expectativas democráticas nuevas. En los regímenes democráticos asociados al individualismo de la universalidad, el sufragio universal significaba que cada persona tenía derecho a la misma proporción de soberanía que todas las demás personas. En la democracia como forma social del individualismo de la singularidad, la persona aspira a ser importante y único a los ojos de otros. Cada persona reclama implícitamente el derecho a ser considerado un as, un experto o un artista, esto es, a que se tengan en cuenta sus ideas y sus juicios y a que se reconozca el valor de estos.

En este nuevo contexto la igualdad no ha perdido en absoluto su importancia. La forma más intolerable de desigualdad aún consiste en no ser tratado como ser humano, en ser rechazado por inútil. De ahí que la idea de igualdad aún implique el deseo de ser considerado alguien, como persona semejante a otras, en vez de ser excluido debido a alguna diferencia específica. En consecuencia, ser reconocido por ser «como» los demás significa ser reconocido por la generalidad humana que uno contiene (volviendo al sentido original de «humanidad» como cualidad de la unidad, sin distinciones). Pero esta generalidad humana ha adquirido un sentido más amplio, más complejo y ha llegado a incluir el deseo de que los demás reconozcan aquello que lo distingue a uno de los demás .-su historia y sus características personales. Nadie quiere ser «reducido a un número»; todos quieren ser alguien.

El advenimiento de la era de la singularidad ha dado lugar a nuevos tipos de conflicto social. Por ejemplo, la creciente aspiración a lograr la autonomía individual a menudo choca con la respuesta estrechamente utilitarista de las empresas. Pero al mismo tiempo, la relación del individuo con la sociedad ha cambiado en formas que han influido profundamente en los puntos de vista acerca de cuáles son las formas más viables de igualdad, así como las formas más tolerables de desigualdad. 
4. ¿SE AVANZA HACIA UNA

NUEVA ERA DE IGUALDAD?

Como consecuencia de los distintos factores mencionados más arriba, la idea de igualdad ha caído en una crisis profunda. Por esta razó, cabe preguntarse cuáles son las opciones:

a) La primera es volver a los males de fines del siglo 19, a la época de la primera globalización, de nacionalismo agresivo, xenofobia y proteccionismo. El proteccionismo nacional se basaba en un concepto puramente negativo de la igualdad. La proximidad se definía como el hecho de pertenecer a una comunidad y por el rechazo de la alienación. Barrès lo expresó crudamente: "La idea de «patria» implica un tipo de desigualdad, pero en perjuicio de los extranjeros». En otras palabras, se trataba de aproximar más a (algunas) personas explotando una relación de desigualdad. A juicio de Barrès, esta igualdad negativa en relación con los extraños se fortalecía por el deseo de organizar otra comunidad de los rechazados, esta vez una comunidad interna y no externa, a saber, «el mundillo de los desconocidos", de los modestos capitalistas y obreros unidos contra los poderosos y los «señores feudales». En realidad, Barrès solió superponer los aspectos interno y externo atacando la «dudosa plutocracia de exóticos». Esta posición extrema muestra claramente que los conceptos de identidad e igualdad siempre se relacionan con una compleja interacción entre proximidad y distancia, individualidad y colectividad, clase y nación.
Lo que distinguía al proteccionismo nacional era el hecho de que representaba un caso extremo, el resultado de una polarización drástica tanto de la identidad como de la igualdad. Asimismo, simplificaba al máximo lo social y de esta manera reducía la idea de igualdad al solo aspecto de pertenecer a una comunidad, que por su parte se reducía a una definición negativa ( $"$ no extraño»). En rigor, para constituir una identidad siempre hay que demarcar, separar, establecer una especie de efecto de reflejo. Los biólogos han observado la forma en que el ser se constituye mediante el reconocimiento del no-ser y la inmunología estudia los mecanismos mediante los cuales ello ocurre. Pero la identidad debe vincularse con una idea adecuadamente positiva de una existencia compartida para producir un sentimiento democrático de pertenencia. Esto lo que distingue a la nación revolucionaria de 1789 de la nación nacionalista del siglo 19. La primera tuvo que ver con la formación de una sociedad de iguales, pero la segunda concibió la integración únicamente en el modo no político de fusión de personas para formar un bloque.

En la actualidad, este concepto nacional proteccionista es el núcleo de los movimientos populistas de Europa y los Estados Unidos.

b) La segunda opción es replantear la cuestión de las desigualdades transformándola de un problema social a uno inter-individual. Esta ha sido la labor de las distintas teorías sobre la justicia distributiva basadas 
en un concepto nuevo de «justo en las igualdades», estructurado en torno a la noción de responsabilidad. En todas partes este concepto ha sido denominado «igualdad de oportunidades» y se ha definido de diversas maneras, que van de lo minimalista a lo radical.

c) Si hoy claramente se necesita mayor redistribución, hay que relegitimizarla. Y ello se logra redefiniendo la igualdad con un criterio universalista. En otras palabras, volviendo al concepto revolucionario, en Francia y los Estados Unidos, de igualdad como relación social y no como medida aritmética. En esa época se consideraba que la igualdad era primordialmente una relación, una manera de construir una sociedad, de producir y vivir en común. Se la concebía como una cualidad democrática y no solo como una medida de la distribución de la riqueza. Esta idea de igualdad como relación se articulaba con otros tres conceptos: semejanza, independencia y ciudadanía. La semejanza corresponde a la igualdad como equivalencia: ser «parecidos» es tener las mismas características fundamentales de modo que las diferencias restantes no afecten la naturaleza de la relación. La independencia es la igualdad como autonomía y se define negativamente como la ausencia de subordinación y en forma positiva como el equilibrio en el intercambio. La ciudadanía involucra igualdad como participación y está constituida por el hecho de pertenecer a una comunidad y por tener actividad cívica. En consecuencia, el proyecto de igualdad como relación se interpretaba en función de un mundo de seres humanos semejantes (o semblables, como diría Tocqueville), una sociedad de individuos autónomos y una comunidad de ciudadanos. La igualdad se concebía así en función de la posición relativa de las personas, de las normas que regían sus interacciones y de los principios en que se basaba su vida en común y, por su parte, estos conceptos correspondían a tres representaciones posibles del vínculo social. Las instituciones subyacentes eran los derechos humanos, el mercado y el sufragio universal. En este contexto se consideraba que las desigualdades económicas solo eran aceptables si no ponían en peligro a las demás formas de igualdad relacional que definían la sociedad de iguales. Estas representaciones, que se formularon en un mundo precapitalista, fueron socavadas por la revolución industrial que dio comienzo a la primera gran crisis de la igualdad. Para superar la segunda gran crisis debemos recapturar el sentido original de igualdad de una manera que resulte apropiada a la época actual.

En la actualidad, los principios de singularidad, reciprocidad y comunalidad pueden devolverle el sentido a la idea de una sociedad de iguales y revivir el proyecto de crearla. Son estos principios los que deben servir de base de legitimidad para elaborar nuevas políticas de redistribución. 